\title{
RASSFIA promoter methylation and expression analysis in normal and neoplastic kidney indicates a role in early tumorigenesis Inga Peters ${ }^{1}$, Kristina Rehmet ${ }^{1}$, Nadine Wilke ${ }^{2}$, Markus A Kuczyk ${ }^{3}$, Jörg Hennenlotter ${ }^{3}$, Tyark Eilers ${ }^{1}$, Stefan Machtens ${ }^{1}$, Udo Jonas ${ }^{1}$ and Jürgen Serth*1
}

Address: ${ }^{1}$ Department of Urology, Medizinische Hochschule Hannover, Hannover, Germany, ${ }^{2}$ Department of Forensic Medicine, Medizinische Hochschule Hannover, Germany and ${ }^{3}$ Department of Urology, Eberhard-Karls University, Tübingen, Germany

Email: Inga Peters - inga-peters@gmx.de; Kristina Rehmet - kristina.rehmet@nuigalway.ie; Nadine Wilke - wilke.nadine@mh-hannover.de; Markus A Kuczyk - markus.kuczyk@med.uni-tuebingen.de; Jörg Hennenlotter - joerg.hennenlotter@med.uni-tuebingen.de;

Tyark Eilers - Eilers.tyark@mh-hannover.de; Stefan Machtens - stefan.machtens@mkh-bgl.de; Udo Jonas - jonas.udo@mh-hannover.de;

Jürgen Serth* - serth.juergen@mh-hannover.de

* Corresponding author

Published: 16 July 2007

Molecular Cancer 2007, 6:49 doi:10.1186/1476-4598-6-49
Received: 5 March 2007

Accepted: 16 July 2007

This article is available from: http://www.molecular-cancer.com/content/6/1/49

(c) 2007 Peters et al; licensee BioMed Central Ltd.

This is an Open Access article distributed under the terms of the Creative Commons Attribution License (http://creativecommons.org/licenses/by/2.0), which permits unrestricted use, distribution, and reproduction in any medium, provided the original work is properly cited.

\begin{abstract}
Background: Epigenetic silencing of the RAS association domain family IA (RASSFIA) tumor suppressor gene promoter has been demonstrated in renal cell carcinoma (RCC) as a result of promoter hypermethylation. Contradictory results have been reported for RASSFIA methylation in normal kidney, thus it is not clear whether a significant difference between RASSFIA methylation in normal and tumor cells of the kidney exists. Moreover, RASSFIA expression has not been characterized in tumors or normal tissue as yet.

Results: Using combined bisulfite restriction analysis (COBRA) we compared RASSFIA methylation in 90 paired tissue samples obtained from primary kidney tumors and corresponding normal tissue. Bisulfite sequence analysis was carried out using both pooled amplicons from the tumor and normal tissue groups and subclones obtained from a single tissue pair. Expression of RASSFIA was analyzed by the use of tissue arrays and immunohistochemistry. We found significantly increased methylation in tumor samples (mean methylation, 20\%) compared to corresponding normal tissues (mean methylation, II\%; $P<0.001$ ). Densely methylated sequences were found both in pooled and individual sequences of normal tissue. Immunohistochemical analysis revealed a significant reduced expression of RASSFIA in most of the tumor samples. Heterogeneous expression patterns of RASSFIA were detected in a subgroup of histologically normal tubular epithelia.
\end{abstract}

Conclusion: Our methylation and expression data support the hypothesis that RASSFIA is involved in early tumorigenesis of renal cell carcinoma. 


\section{Background}

Renal cell carcinoma (RCC) accounts for 2-3\% of human malignancies and is the seventh most frequent cause of tumor-dependent death among men [1,2]. The most common histological subtypes of sporadic kidney tumors are clear cell RCC (CC-RCC) and papillary tumors [3].

Tumorigenesis of CC-RCC is frequently associated with loss and/or alteration of the short arm of chromosome 3 [4]. At least two tumor suppressors are localized on 3p213p25, the von Hippel-Lindau (VHL) and the RAS association domain family $1 \mathrm{~A}$ (RASSF1A) genes, both found to be altered in sporadic RCC. Chromosomal alterations, point mutations and epigenetic silencing have been described to affect VHL function [5-7], while RASSF1A has frequently been detected to undergo promoter hypermethylation and epigenetic silencing in CC-RCC [8-11].

RASSF1A is functionally involved in cell cycle control, microtubule stabilization, cellular adhesion and motility as well as apoptosis (reviewed in [12]). Therefore, depletion of RASSF1A is associated with accelerated mitotic progression and an increased risk for chromosomal defects [13-15], enhanced cellular motility [16] and with increased tumor susceptibility in knock-out mice [17].

The multifaceted function of RASSF1A as well as its frequently detected epigenetic silencing suggests an essential role in carcinogenesis. Therefore, findings regarding RASSF1A methylation in histopathologically normal kidney tissue isolated adjacent to tumor tissue or from autopsy samples $[8,18,19]$ might be indicative for an involvement of RASSF1A in the early tumorigenesis of CC-RCC. On the other hand, significant methylation in normal tissue has not been described in other reports $[9,10,20]$ and a quantitative study questions that significant differences in RASSF1A methylation can be found comparing methylation levels in CC-RCC and corresponding normal tissue samples [11].

The detection of a methylation frequency in tumor tissue matching that in normal tissue would indicate that RASSF1A methylation in kidney is more likely to be independent from CC-RCC tumorigenesis. Conversely, if methylation could be found in normal tissue, which expands following tumor development, a role of RASSF1A in early tumorigenesis is implied. Thus, both quality and quantitative extent of methylation in histopathologically normal and tumoral tissue of tumor-bearing kidney requires systematic analysis to demonstrate whether significant methylation can be found in normal cells and a substantially increased methylation can be detected within neoplastic cells. Moreover, considering that so far the presence of RASSF1A protein has been analyzed solely in fully transformed or embryonic cell lines $[14,16]$, it is an important issue to examine whether methylation levels can be correlated to a corresponding expression of RASSF1A in normal and tumor tissues.

In the present study, we have quantitatively measured promoter methylation of the RASSF1A gene in paired samples of CC-RCC and corresponding normal renal tissue. Furthermore, the presence of RASSF1A protein in tumors and histopathologically normal parenchyma was analyzed using tissue arrays and immunohistochemistry. Methylation was found to be significantly increased within tumor cells of tissue pairs analyzed. Correspondingly, almost complete loss of RASSF1A expression was observed in tumor cells, while normal tubular epithelial cells largely demonstrated strong immunopositivity. However, a subgroup of tissues exhibited a heterogeneous expression pattern including partial loss of RASSF1A protein.

\section{Results \\ Quantitation of RASSFIA methylation in paired tumoral and normal tissue samples}

Methylation was first quantitatively analyzed in tumor vs. paired normal tissue from each individual patient using COBRA (Fig. 2), Fig. 3a).

It is obvious from Fig. 3a that most tumors and normal tissues demonstrate relative methylation levels above the analytical detection limit, however, a relative increase of methylation in tumors when compared to the paired normal tissue was observed in $39(86.7 \%)$ of 45 tumors (Fig. $3 b$ ). This finding is statistically significant (t-test for paired samples, $\mathrm{P}<0.001$ ). Note that five tissue pairs demonstrated an apparently decreased relative methylation in tumors which possibly can be deduced from small measurement variations considering that the corresponding methylation levels approximated the methodical limit of detection.

Mean degrees of methylation of $20 \%$ and $11 \%$ were determined for the tumoral and normal tissues.

\section{Bisulfite sequence analysis for comparison of tumoral and normal tissues}

Bisulfite sequencing analysis was carried out using in each case 50 subclones obtained from an individual normal and tumoral tissue pair following bisulfite conversion and amplification (Fig. 4). We found 102 (12.8\%) and 165 (20.6\%) of totally analyzed 800 CpG sites to be methylated in normal and paired tumoral tissue samples, respectively $(\mathrm{P}<0.001$, chi-square test). Dense promoter methylation of more than 10 methylated $\mathrm{CpG}$ sites per clone was more frequently found in the tumor sample ( $\mathrm{n}$ $=11$ ) when compared to the paired normal tissue $(\mathrm{n}=1$; see Fig. 5). 


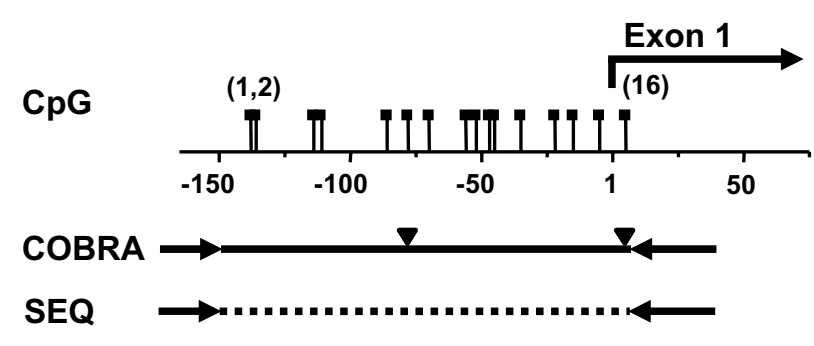

Figure I

Analyzed promoter region of the RASSFIA gene. CpG sites in the promoter region of the RASSFIA gene analyzed by combined bisulfite restriction analysis (COBRA) and bisulfite sequence analysis. Numbers refer to the position of transcription start site while bracketed numbers indicate $C_{p G}$ sites. Solid triangles show Taql restrictions sites used for COBRA. The solid and dashed lines indicate sequences amplified for COBRA and sequence analysis following bisulfite conversion of DNA. Inner primer positions were indicated by solid arrows.

In addition to the sequence analysis of the individual kidney tissue pair, we conducted an in-group sequence comparison of pooled amplicons obtained from the tumor and normal tissues following conversion, amplification and normalization of DNA. Thirty-five (5.5\%) and 67 $(10.5 \%)$ of $640 \mathrm{CpG}$ sites analyzed in total were found to be methylated in the normal and tumor tissue group, respectively (Fig. 5). Assuming each CpG methylation as an independent event, statistical analysis showed that tumor and normal tissue groups demonstrated significant differences in methylation frequency $(P<0.001$, chisquare test).

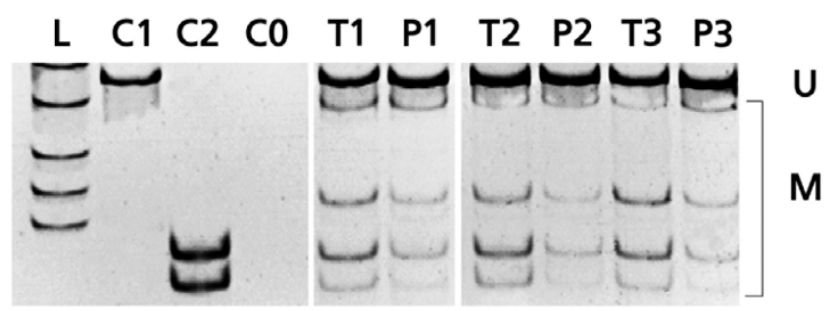

Figure 2

Methylation analysis of paired tumor and normal kidney samples using COBRA. The degree of methylation in kidney samples was analyzed using COBRA and video densitometry for determination of methylated $(M)$ and unmethylated $(U)$ band signals: $L$, length marker; $\mathrm{Cl}$, negative methylation control (plasmid pCU); $\mathrm{C} 2$, positive methylation control (plasmid PCM); CO, negative control; TI - T3, tumoral and PI - P3, normal paired tissue samples.
Analysis of RASSF I A promoter methylation and RASSF I A expression in CaSki and HEK293 cell lines

To detect RASSF1A protein in paraffin embedded tumoral and normal kidney tissue we first examined the specificity of the RASSF1A antibody using paraffin embedded sediments of control cell lines CaSki and HEK293. We found strong immunopositivity in the cytoplasm of CaSki cells (Fig. 6a[i]). This corresponds with a lack of RASSF1A promoter methylation as detected by COBRA (Fig. 6a). Moreover, immunopositivity can be specifically blocked by the peptide used for immunization (Fig. 6a[ii]). On the contrary, we detected almost complete methylation of RASSF1A in the embryonic kidney cell line HEK293, which is associated with significantly decreased cytoplasmic immunopositivity (Fig. 6b[i]). As expected this finding is not affected by peptide blocking of the antibody (Fig. 6b[ii]). Faint nuclear positivity, appears as heterogeneous pattern in antibody incubations of HEK293 independently of the presence of a blocking peptide, suggesting a residual unspecific nuclear binding of the polyclonal antibody. However, only cytoplasmic immunopositivity has been considered for evaluation of tissue sections.

\section{Detection of RASSFIA protein in tumoral and normal tissue samples of the kidney}

Using immunohistochemistry and tissue arrays obtained from paraffin embedded renal tissue samples we analyzed 60 tissue pairs for expression of RASSF1A. We found that $33(55 \%)$ of tumors demonstrate to a great extent loss of cytoplasmic RASSF1A protein corresponding to a labeling index of less than $10 \%$ of immunopositive stained tumor cells (Fig. 6c). In contrast, the vast majority of normal tubular epithelial cells showed strong cytoplasmic signals for RASSF1A protein (Fig. 6d). However, a subgroup of normal tissues was identified to exhibit loss of immunopositivity in some of the morphologically normal renal tubular epithelia (Fig. 6e). Moreover, a significant heterogeneity of signals appearing as a mosaic-like staining pattern was observed within single renal tubules (Fig. 6f). Note that both inter- and intratubular heterogeneous expression of RASSF1A has also been observed using immunofluorescence detection and the mouse monoclonal antibody (data not shown).

\section{Discussion}

RASSF1A promoter methylation has been shown to be associated with gene silencing in RCC $[8,9]$. However, discordant results were reported for RASSF1A promoter methylation occurring in tumor-surrounding, i.e. histopathologically tumor-free renal tissue [8-10,18,20]. Moreover, a quantitative study found no difference between normal and tumoral tissue regarding the frequency of methylation or a normalized methylation index of both tissues [11]. Therefore, as long as a significant 
A

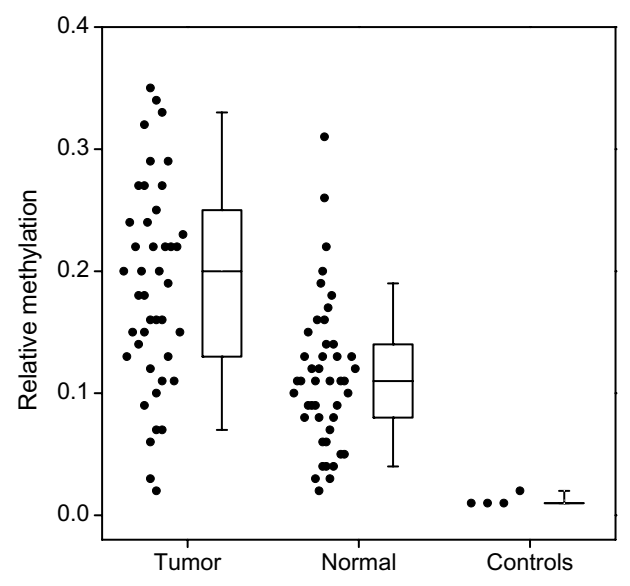

B

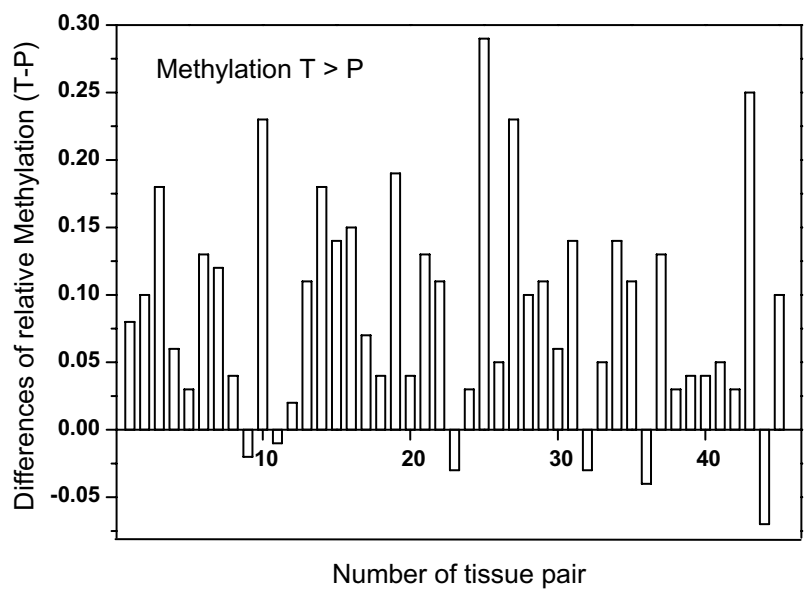

Figure 3

Results of quantitative methylation analysis of tissue pairs. a. Primary data and box plot illustration for in group comparison of relative methylation of RASSFIA promoter as measured by COBRA in 45 tumor and paired normal renal tissue samples as well as plasmid - DNA negative controls. Note that 44 (98\%) tumors and 44 (98\%) of 45 paired normal tissues demonstrated relative methylation greater than $2.75 \%$ determined as limit of analytical sensitivity. b. Quantitative methylation analysis of the RASSFIA promoter in 45 tumoral and normal tissue pairs using combined bisulfite restriction analysis (COBRA). Note that most of the tumors demonstrate a substantial relative increase in methylation when compared to their corresponding normal tissue $(P<0.001)$

increase of tumor-dependent RASSF1A methylation cannot be shown in CC-RCC, it seems debatable whether RASSF1A substantially contributes to RCC tumorigenesis.

Our study is the first to specifically address the comparison of RASSF1A methylation levels detectable in paired samples of normal and tumor tissue. Our quantitative methylation analysis focused CpG sites localized directly adjacent to the start of RASSF1A transcription, a promoter region that has been described to cause gene silencing of RASSF1A [21,22]. The results of our quantitative data clearly show that the degree of relative methylation is significantly increased within tumor tissue of individual tissue pairs. However, a single tissue pair out of 45 demonstrated a $7 \%$ decrease of relative methylation in the tumor sample which we hypothetically explain by tissue heterogeneity due to the presence of undetected fibroblasts or tumor infiltrating lymphocytes.

Increased methylation as detected in most tumors can be explained by a higher proportion of low grade methylation, an increased number of highly methylated promoters or a combination of both effects. According to our bisulfite sequencing analysis of both an individual tissue pair and the tumor and normal groups as a whole, the higher degree of relative methylation observed in tumors can be attributed clearly to a higher proportion of densely methylated sequences present in tumors. Although the absolute numbers for the relative degree of methylation determined by COBRA and calculated on the basis of bisulfite sequencing slightly differ, a nearly identical ratio of methylation in tumor vs. normal tissue samples was obtained for both methods. Thus, the results of our comparative methylation analysis demonstrate a statistically significant expansion of RASSF1A promoter methylation in the course of RCC development.

However, our sequencing analyses also demonstrated that dense methylation, though detected more frequently in tumor cells, is also sporadically observed in normal tissue thereby confirming results described in some of the earlier analyses of RASSF1A methylation in kidney tissue $[8,18,19]$. Moreover, methylation data obtained for tumors and normal tissue overall matches the results of our expression analysis. Accordingly, expression analysis demonstrated strong signals for RASSF1A protein in the control cell line as well as in the cytoplasm of most of the normal tubular cells. In contrast, a significant loss of protein was detected within most cells of tumor tissue. Thus, protein levels detected immunohistochemically in a large 


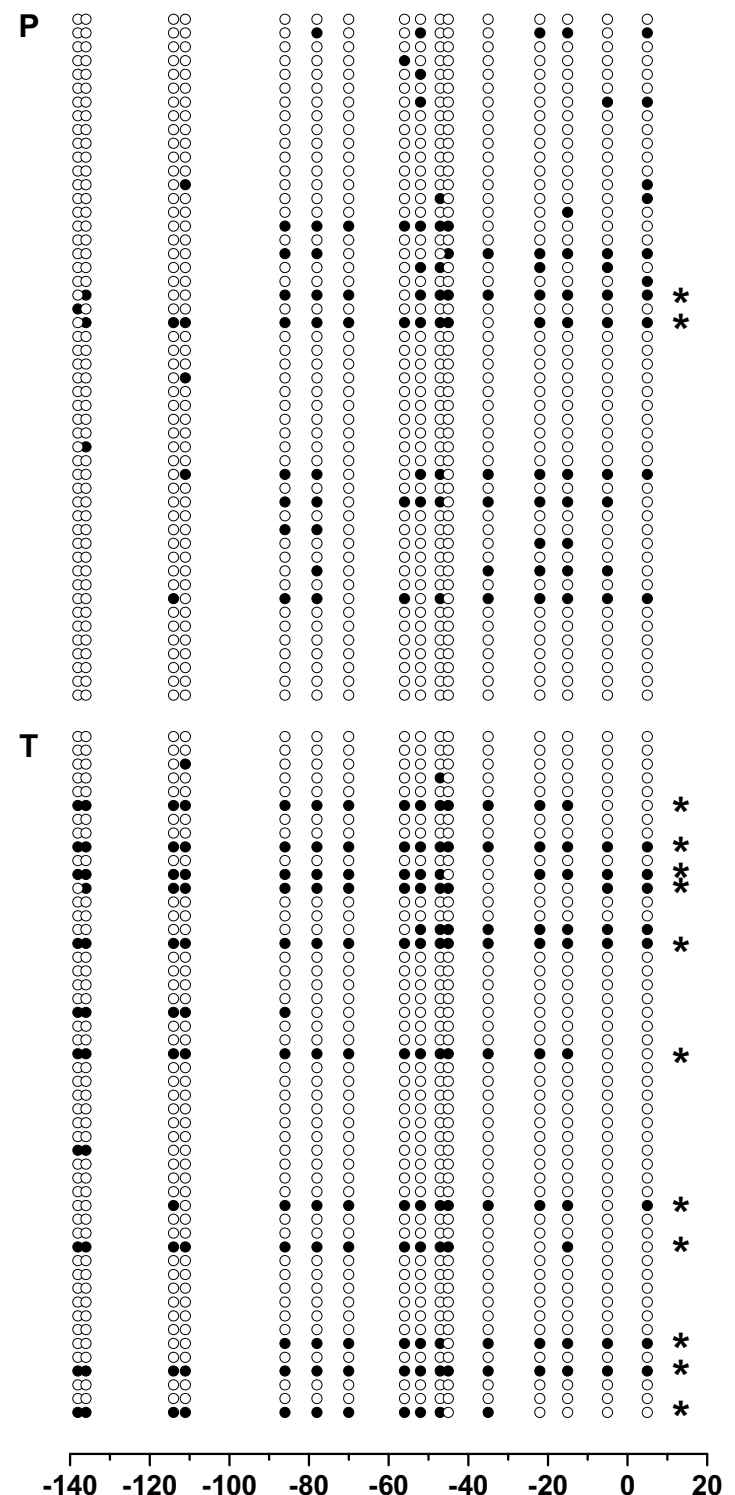

Figure 4

Bisulfite sequence analysis of RASSFIA promoter methylation in one tissue pair of tumoral and normal tissue. RASSFIA promoter amplicons obtained from a single tumoral $(T)$ and its paired normal $(P)$ tissue sample were subcloned and each 50 clones analyzed by the use of bisulfite sequencing. For each clone the methylation status of analyzed CPG sites is shown (solid circles: methylation, open circles: no methylation). Numbers on $\mathbf{x}$-axis refer to base pair positions as indicated in Figure I. Asterisks indicate amplicons derived from densely methylated promoters demonstrating at least II methylated CPG sites.

part of tumors are in concordance with a gene silencing of RASSF1A in RCC as described previously [8-10].

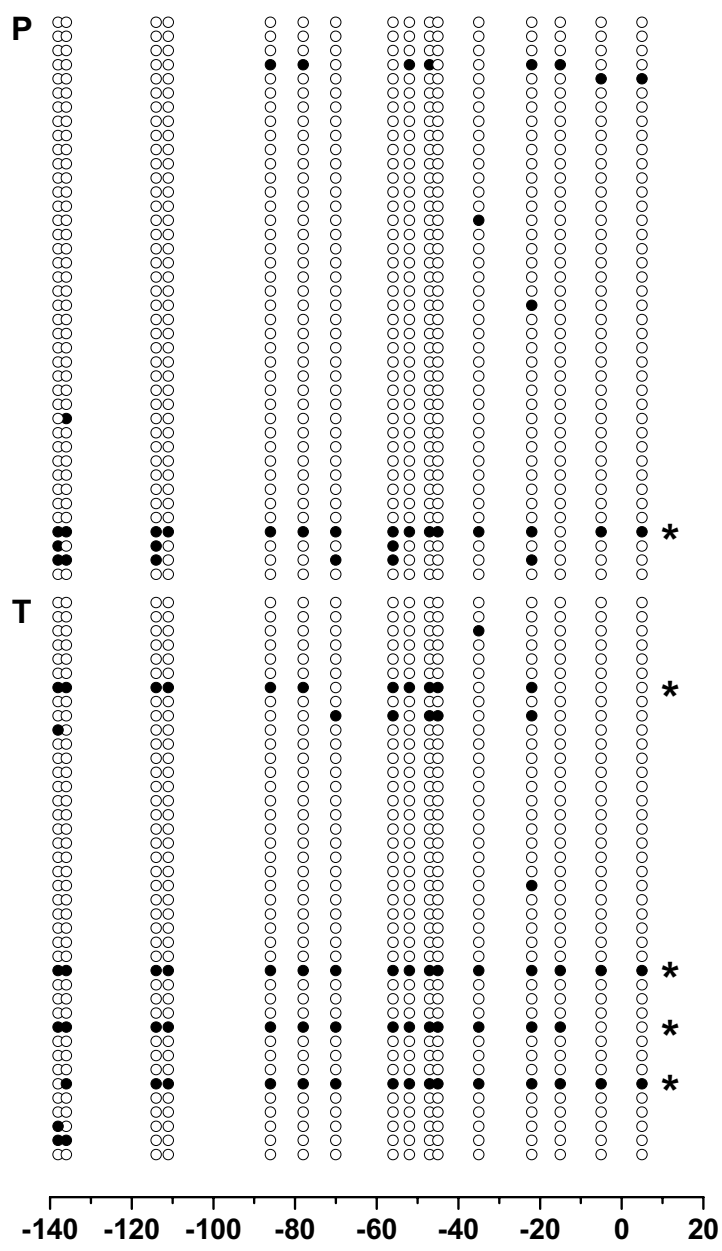

\section{Figure 5}

Bisulfite sequencing of pooled tumoral and normal RASSFIA promoters. RASSFIA promoter amplicons from 42 tumoral and 42 normal tissue samples were normalized, pooled, subcloned and each 40 subclones of the tumor $(T)$ and normal $(\mathrm{P})$ group analyzed by bisulfite sequencing. For each clone the methylation status of analyzed $C_{P G}$ sites is shown (solid circles: methylation, open circles: no methylation). Numbers on $\mathbf{x}$-axis refer to base pair positions as indicated in Figure I. Asterisks indicate amplicons derived from densely methylated promoters demonstrating at least II methylated $C_{P} G$ sites.

Most interestingly, we also observed in normal tissue samples a partial loss of signals for RASSF1A protein, appearing as a heterogeneous staining pattern, which is in line with the detection of a subgroup of densely methylated promoter sequences in normal tissue. Similar findings have been described for methylation and expression of 
a

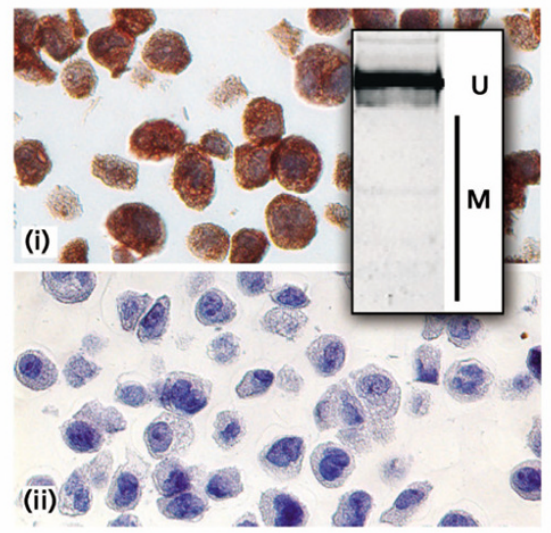

C

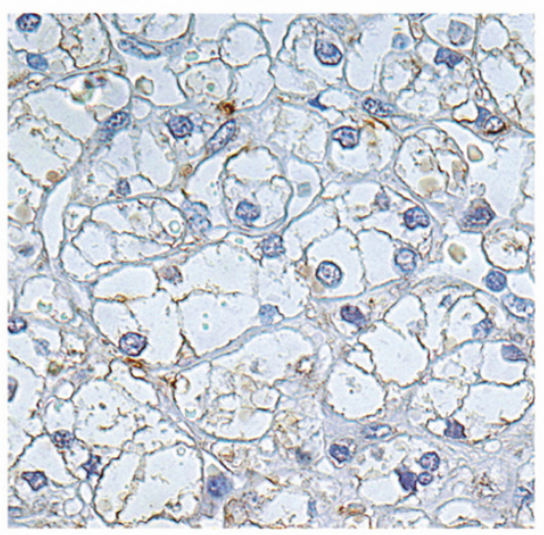

e

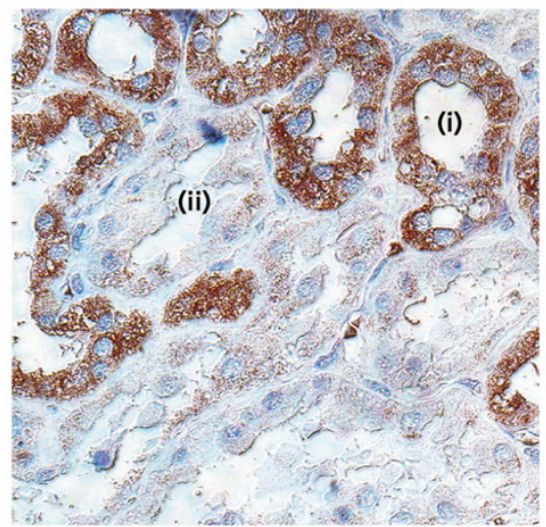

b

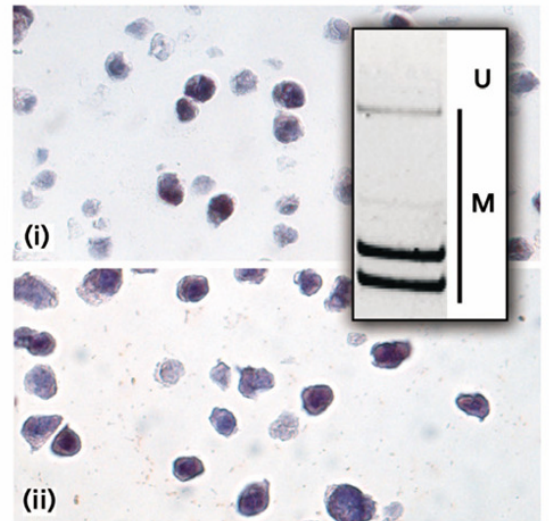

d

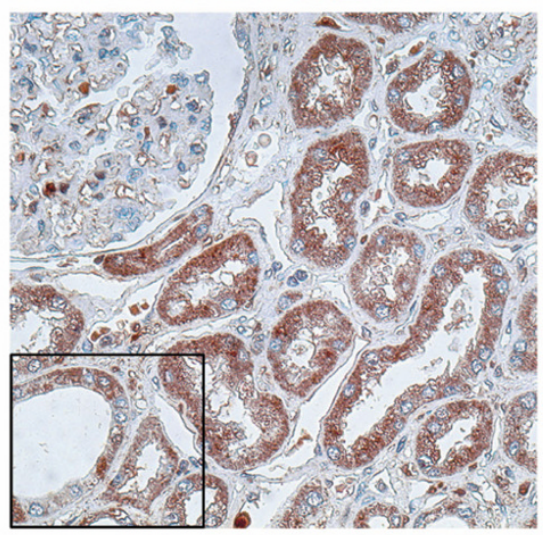

f

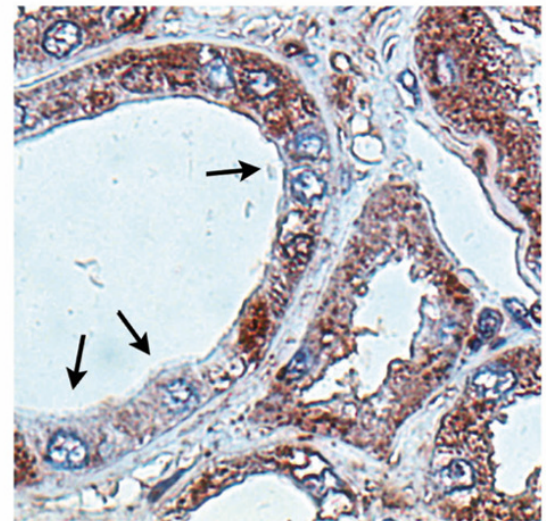

Figure 6

Detection of RASSF I A protein in clear cell RCC and control cell lines. Paraffin-embedded tissue samples obtained from renal tumor and paired normal tissues were analyzed for presence of RASSFIA protein using immunohistochemistry (counterstaining hematoxylin). a. Immunohistochemical positive control: CaSki cell line demonstrating absence of RASSFIA promoter methylation in COBRA (see box; $U$, unmethylated signals; $M$, methylation signals) and immunopositivity depending on the absence (i) or presence (ii) of an antibody blocking peptide, respectively. b. Immunohistochemical negative control: $\mathrm{HEK} 293$ cell line showing strong methylation in COBRA (see box; $U$, unmethylated signals; $M$, methylation signals). Only residual unspecific nuclear immunopositivity can be observed, which is independent from the absence (i) and presence (ii) of an antibody blocking peptide. c. Tumor cells of a clear cell RCC (magnification, 400x). d. Histopathologically normal tissue with immunopositive epithelial tubular cells (magnification, 400x). e. Heterogeneous staining patterns demonstrating immunopositive (i) and negative (ii) epithelia in renal tubules. f. Mosaic-like staining signals in a single tubular epithelium (see arrows, magnified from panel $d$ as indicated). 
the MLH1 and $p 14$ genes and were designated as "epigenetic mosaicism" [23-25].

It has been described that RASSF1A translocates during mitosis and reorganization of microtubules [14], thus leading to a loss of cytoplasmic signals. However, apparent mitotic activity was not detected in these cells, neither in extent nor in frequency explaining the observed expression patterns.

We therefore conclude that the sporadic hypermethylation observed in normal tissue corresponds to a partial loss of RASSF1A expression in normal tubular epithelium of the kidney leading to epigenetic mosaicism of RASSF1A as a possible premalignant event in CC-RCC tumorigenesis. To characterize the role of RASSF1A in early tumorigenesis of the kidney further functional studies are required.

\section{Conclusion}

Our methylation and expression analyses of RASSF1A support the hypothesis that infrequent hypermethylation of the RASSF1A promoter in normal cells precedes the formation of tumor cells, thus explaining the more frequently detected hypermethylation found in most CCRCCs. The partial loss of RASS1A expression driven by hypermethylation of the gene promoter could be a premalignant event in early tumorigenesis in the kidney.

\section{Methods}

\section{Tissue samples and DNA extraction}

Paired tumoral and normal specimens were prepared from 45 primary clear cell RCCs after nephrectomy (table 1 for patient characteristics). Normal tissue samples were obtained from histologically benign renal parenchyma distant to the tumor-bearing region of the kidney. All tissue samples were snap-frozen in liquid nitrogen and stored at $-80^{\circ} \mathrm{C}$. Following preparation of $5 \mu \mathrm{m}$ frozen sections and hematoxylin-eosin staining, two serial cuttings of each appropriate tissue - i.e. tumor tissue consisting at least of $75 \%$ tumor cells and histopathologically normal tissue - were subjected to proteinase $\mathrm{K}$ digestion. One section was dedicated to control quality and quantity of extracted DNA using agarose gel electrophoresis and videodensitometrical analysis. The remaining aliquot was utilized for subsequent bisulfite conversion. In summary, tissue sections were incubated on the slide using $0.5 \mathrm{mg}$ proteinase $\mathrm{K}$ in $50 \mu \mathrm{L}$ of digestion buffer $(50 \mathrm{mM} \mathrm{KCl}, 10$ $\mathrm{mM}$ Tris- $\mathrm{HCl} \mathrm{pH}$ 8.3, $0.5 \mathrm{mM}$ EDTA, $0.01 \% \mathrm{w} / \mathrm{v}$ gelatin, $0.5 \%$ Tween 20 ) for $20 \mathrm{~min}$ at room temperature in a humid chamber. Digestion of tissue sections was completed after transfer of partially digested sections into a 1.5 $\mathrm{mL}$ reaction tube and incubation at $50^{\circ} \mathrm{C}$ for another $3 \mathrm{~h}$. DNA was extracted using standard phenol/chloroform extraction and phase lock tubes (Light $0.5 \mathrm{~mL}$, Eppendorf, Wesseling-Berzdorf, Germany) for phase separation.

\section{Bisulfite conversion of DNA}

Bisulfite conversion of genomic DNA was carried out according to Herman et al. [26]. To precipitate the converted DNA, the conversion mixture, $800 \mu \mathrm{l}$ water, $1 \mu \mathrm{g}$ salmon sperm DNA, $20 \mu \mathrm{L} \mathrm{MgCl}_{2}(1 \mathrm{M})$ and $800 \mu \mathrm{L}$ of polyethylene glycol (PEG) 1,500 was mixed by inversion, incubated for $1 \mathrm{~h}$ at $0^{\circ} \mathrm{C}$ and centrifuged for $20 \mathrm{~min}$ $\left(15,000 \mathrm{~g}, 4^{\circ} \mathrm{C}\right)$. Finally, the precipitated DNA was dissolved and desulfonated by addition of $100 \mu \mathrm{L} \mathrm{NaOH}$ $(0.3 \mathrm{M})$ and incubation at room temperature for $15 \mathrm{~min}$. Following standard ethanol precipitation the DNA was resuspended in $50 \mu \mathrm{L}$ Tris-EDTA buffer $(10 \mathrm{mM}, \mathrm{pH} 8.0)$ and stored at $-80^{\circ} \mathrm{C}$.

\section{Methylation analysis}

CpG sites in RASSF1A promoter region analyzed by combined bisulfite restriction analysis (COBRA) and bisulfite sequence analysis are shown in Figure 1. Plasmids pCM (converted methylated) and pCU (converted unmethylated), were generated by cloning amplicons of methylated and unmethylated native promoter sequence following bisulfite conversion and then applied as reference sequences for quantitative methylation analysis.

Combined bisulfite restriction analysis was carried out using semi-nested PCR and primers as described previously [21]. A uniform amplification of the converted methylated and unmethylated sequences could be maintained for copy numbers equal or greater than $5 \times 10^{3}$ sequence copies (data not shown). For first round amplification $5 \mu \mathrm{L}$ of converted DNA, $0.4 \mu \mathrm{M}$ of each primer, CU001 (5'-GTT TTG GTA GTT TAA TGA GTT TAG GTT TTT T-3') and CL002 (5'-ACC CTC TTC CTC TAA CAC AAT AAA ACT AAC C-3'), 1 unit Taq polymerase (Quiagen, Hilden, Germany), $0.2 \mathrm{mM}$ dNTPs and $5.5 \mu \mathrm{L}$ of reaction buffer were mixed (total volume $50 \mu \mathrm{L}$ ) and subjected to PCR (initial denaturation at $95^{\circ} \mathrm{C}$ for $180 \mathrm{sec}$; 25 cycles with $45 \mathrm{sec}$ of denaturation at $95^{\circ} \mathrm{C}$, annealing at $63^{\circ} \mathrm{C}$ for $1 \mathrm{~min}$, primer extension at $73^{\circ} \mathrm{C}$ for $45 \mathrm{sec}$ and $180 \mathrm{sec}$ at $72^{\circ} \mathrm{C}$ for the last cycle). The second PCR product was generated using $1 \mu \mathrm{L}$ of first PCR product and primers CU001 and CNO03 (5'-CCC CAC AAT CCC TAC ACC CAA AT-3'). PCR conditions were identical to the first PCR except an annealing temperature of $56^{\circ} \mathrm{C}$ was applied in a total PCR volume of $25 \mu \mathrm{L}$. For restriction digest $10 \mu \mathrm{L}$ of the second PCR, 3.3 units of Taq I (New England Biolabs, USA), water and the corresponding restriction buffer were incubated over night at $65^{\circ} \mathrm{C}$ in a final volume of $20 \mu \mathrm{L}$ and subsequently analyzed using PAGE and video densitometry. 
Table I: Pathological and clinical characterization of tumor group.

\begin{tabular}{lc}
\hline Number of patients & 45 \\
Mean, age in years & 61 \\
Males, $\mathrm{n}(\%)$ & $34(75.5)$ \\
Females, $\mathrm{n}(\%)$ & $1 \mathrm{l}(24.5)$ \\
Pathologic Stage, $\mathrm{n}(\%)$ & $18(40)$ \\
TI & $5(11)$ \\
T2 & $20(45)$ \\
T3 & $2(4)$ \\
T4 & 20 \\
\hline
\end{tabular}

To determine the relative degree of methylation, fragments corresponding to methylated sequences and the uncut band indicating unmethylated sequences were quantified by video densitometry and corrected for molecular weight. The relative degree of methylation in each sample was calculated by dividing the sum of methylated signals by the sum of all signals. To demonstrate that COBRA can be applied for determination of the relative degree of RASSF1A promoter methylation, defined mixtures of corresponding plasmid DNA and of DNA isolated from HEK293 and CaSki cell lines were measured. The relative degree of methylation measured by COBRA was then compared to the known input ratio of methylated and unmethylated sequences. Linearity was observed for almost two orders of magnitude, both for the plasmid and cell line controls. Using the threefold standard deviation of signals obtained from multiple negative controls, the analytical sensitivity of COBRA could be calculated to be $2.75 \%$ relative methylation (Fig. $3 a$ ).

\section{Bisulfite sequencing}

For sequence analysis amplicons were subcloned into pGEM-T Easy vectors (Promega, Mannheim, Germany) and sequenced using SP6 primer, BigDye Terminator v1.1 Cycle Sequencing Kit on an ABI 3100 Avant automated sequencer (Applied Biosystems, Darmstadt, Germany) according to the manufacturer's protocols or by custom sequence analysis (MWG Biotech, Ebersberg, Germany). Pool sequencing analysis was carried out following normalization of 42 amplicons obtained each from the tumor and normal tissue groups and subcloning as described above.

\section{Immunohistochemistry}

Immunohistochemical analysis of renal paraffin embedded tissue samples arranged in an array format and signal amplification using tyramide was carried out as described previously [27-29]. For detection of RASSF1A protein an affinity purified goat polyclonal antibody (RASF1-N15, Santa Cruz Biotechnology, USA) and a mouse monoclonal antibody (Anti-human RASSF1A mAb, clone 3F3, Acris, Germany) were applied. RASF1-N15 specifically detects the N-terminus of RASSF1 isoforms A, D, F, G. However, the major transcripts are represented by isoforms A and C [21], whereas other isoforms seem to be expressed rarely in a tissue-specific manner such as RASSF1D and E [30]. Expression of RASSF isoform $\mathrm{C}$ has been localized to the nucleus [14], thus cytoplasmic signals obtained by immunostaining using RASF1-N15 antibody were considered to be due to RASSF1A expression.

\section{Statistical analysis}

Statistical analyses were performed using the SPSS statistical software (statistical package for social sciences, SPSS, Inc., Chicago, IL). P-values of $\leq 0.05$ were considered statistically significant.

\section{Competing interests}

The author(s) declare that they have no competing interests.

\section{Authors' contributions}

IP carried out the methylation analyses and participated in the sequence analysis and drafting of the manuscript and figures. KR participated in sequence analysis. NW and $\mathrm{JH}$ were engaged in isolation and characterization of tissue samples. MK and SM participated in the design of the study and data analysis. TE assisted in method development for DNA precipitation following bisulfite treatment. UJ assisted with general scientific discussion. JS conceived of the study, participated in its design, statistical analysis and coordination and wrote the original and final versions of the manuscript.

All authors read and approved the final manuscript.

\section{Acknowledgements}

We thank Margrit Hepke and Marianne Kuhls for technical assistance.

\section{References}

I. Landis SH, Murray T, Bolden S, Wingo PA: Cancer statistics, 1999. CA Cancer J Clin 1999, 49( I):8-3I, I.

2. Jemal A, Murray T, Ward E, Samuels A, Tiwari RC, Ghafoor A, Feuer EJ, Thun MJ: Cancer statistics, 2005. CA Cancer J Clin 2005, 55(I): $10-30$. 
3. Thoenes W, Storkel S, Rumpelt HJ: Histopathology and classification of renal cell tumors (adenomas, oncocytomas and carcinomas). The basic cytological and histopathological elements and their use for diagnostics. Pathol Res Pract 1986, I8I(2): | $25-143$

4. Zbar B, Brauch H, Talmadge C, Linehan M: Loss of alleles of loci on the short arm of chromosome 3 in renal cell carcinoma. Nature 1987, 327(6 I 24):72I-724.

5. Gnarra JR, Tory K, Weng Y, Schmidt L, Wei MH, Li H, Latif F, Liu S, Chen F, Duh FM, et al.: Mutations of the VHL tumour suppressor gene in renal carcinoma. Nat Genet 1994, 7(1):85-90.

6. Shuin T, Kondo K, Torigoe S, Kishida T, Kubota Y, Hosaka M, Nagashima $Y$, Kitamura H, Latif F, Zbar B, et al.: Frequent somatic mutations and loss of heterozygosity of the von HippelLindau tumor suppressor gene in primary human renal cell carcinomas. Cancer Res I 994, 54(I I):2852-2855.

7. Herman JG, Latif F, Weng Y, Lerman MI, Zbar B, Liu S, Samid D, Duan DS, Gnarra JR, Linehan WM, et al.: Silencing of the VHL tumorsuppressor gene by DNA methylation in renal carcinoma. Proc Natl Acad Sci U S A 1994, 9 I(2 I):9700-9704.

8. Dreijerink K, Braga E, Kuzmin I, Geil L, Duh FM, Angeloni D, Zbar B, Lerman MI, Stanbridge EJ, Minna JD, Protopopov A, Li J, Kashuba V, Klein G, Zabarovsky ER: The candidate tumor suppressor gene, RASSFIA, from human chromosome $3 \mathrm{p} 21.3$ is involved in kidney tumorigenesis. Proc Natl Acad Sci U S A 200I, 98(I 3):7504-7509.

9. Morrissey C, Martinez A, Zatyka M, Agathanggelou A, Honorio S, Astuti D, Morgan NV, Moch H, Richards FM, Kishida T, Yao M, Schraml P, Latif F, Maher ER: Epigenetic inactivation of the RASSFIA 3p2I.3 tumor suppressor gene in both clear cell and papillary renal cell carcinoma. Cancer Res 200I, $6 I(19): 7277-7281$.

10. Yoon JH, Dammann R, Pfeifer GP: Hypermethylation of the CpG island of the RASSFIA gene in ovarian and renal cell carcinomas. Int J Cancer 200I, 94(2):2 I2-2I7.

11. Gonzalgo ML, Yegnasubramanian S, Yan G, Rogers CG, Nicol TL, Nelson WG, Pavlovich CP: Molecular profiling and classification of sporadic renal cell carcinoma by quantitative methylation analysis. Clin Cancer Res 2004, I O(2 I):7276-7283.

12. Agathanggelou A, Cooper WN, Latif F: Role of the Ras-association domain family $\mathrm{I}$ tumor suppressor gene in human cancers. Cancer Res 2005, 65(9):3497-3508.

13. Mathe E: RASSFIA, the new guardian of mitosis. Nat Genet 2004, 36(2): $117-118$.

14. Song MS, Song SJ, Ayad NG, Chang JS, Lee JH, Hong HK, Lee H, Choi N, Kim J, Kim H, Kim JW, Choi EJ, Kirschner MW, Lim DS: The tumour suppressor RASSF IA regulates mitosis by inhibiting the APC-Cdc20 complex. Nature cell biology 2004, 6(2):129-137.

15. Dallol A, Cooper WN, AI-Mulla F, Agathanggelou A, Maher ER, Latif F: Depletion of the Ras association domain family I, isoform A-associated novel microtubule-associated protein, CI9ORF5/MAPIS, causes mitotic abnormalities. Cancer Res 2007, 67(2):492-500.

16. Dallol A, Agathanggelou A, Tommasi S, Pfeifer GP, Maher ER, Latif F: Involvement of the RASSF IA tumor suppressor gene in controlling cell migration. Cancer Res 2005, 65(I 7):7653-7659.

17. Tommasi S, Dammann R, Zhang Z, Wang Y, Liu L, Tsark WM, Wilczynski SP, Li J, You M, Pfeifer GP: Tumor susceptibility of Rassfla knockout mice. Cancer Res 2005, 65(I):92-98.

18. Tokinaga K, Okuda H, Nomura A, Ashida S, Furihata M, Shuin T: Hypermethylation of the RASSFIA tumor suppressor gene in Japanese clear cell renal cell carcinoma. Oncol Rep 2004, 1 2(4):805-810.

19. Waki T, Tamura G, Sato M, Motoyama T: Age-related methylation of tumor suppressor and tumor-related genes: an analysis of autopsy samples. Oncogene 2003, 22(26):4I 28-4I33.

20. Dulaimi E, Ibanez de Caceres I, Uzzo RG, Al-Saleem T, Greenberg RE, Polascik TJ, Babb JS, Grizzle WE, Cairns P: Promoter hypermethylation profile of kidney cancer. Clin Cancer Res 2004, I ( 12 Pt I):3972-3979.

21. Dammann R, Li C, Yoon JH, Chin PL, Bates S, Pfeifer GP: Epigenetic inactivation of a RAS association domain family protein from the lung tumour suppressor locus 3p21.3. Nat Genet 2000, 25(3):315-319.

22. Yan PS, Shi H, Rahmatpanah F, Hsiau TH, Hsiau AH, Leu YW, Liu JC, Huang TH: Differential distribution of DNA methylation within the RASSFIA CpG island in breast cancer. Cancer Res 2003, 63(19):6178-6186

23. Issa JP: Age-related epigenetic changes and the immune system. Clin Immunol 2003, I09(I): 103-108.

24. Nakagawa H, Nuovo GJ, Zervos EE, Martin EW Jr., Salovaara R, Aaltonen LA, de la Chapelle A: Age-related hypermethylation of the 5 ' region of $\mathrm{MLHI}$ in normal colonic mucosa is associated with microsatellite-unstable colorectal cancer development. Cancer Res 200I, 6I(19):699I-6995.

25. Shen L, Kondo Y, Hamilton SR, Rashid A, Issa JP: PI4 methylation in human colon cancer is associated with microsatellite instability and wild-type p53. Gastroenterology 2003, I 24(3):626-633.

26. Herman JG, Graff JR, Myohanen S, Nelkin BD, Baylin SB: Methylation-specific PCR: a novel PCR assay for methylation status of CpG islands. Proc Natl Acad Sci U S A 1996, 93( I 8):982I-9826.

27. Ikuerowo SO, Kuczyk MA, Mengel M, van der Heyde E, Shittu OB, Vaske B, Jonas U, Machtens S, Serth J: Alteration of subcellular and cellular expression patterns of cyclin $B I$ in renal cell carcinoma is significantly related to clinical progression and survival of patients. Int J Cancer 2006, I I 9(4):867-874.

28. von Wasielewski R, Mengel M, Gignac S, Wilkens L, Werner M, Georgii A: Tyramine amplification technique in routine immunohistochemistry. J Histochem Cytochem 1997, 45(II): I 1455-1459.

29. Mengel M, Werner M, von Wasielewski R: Concentration dependent and adverse effects in immunohistochemistry using the tyramine amplification technique. Histochem J 1999, 3I(3): $195-200$

30. Burbee DG, Forgacs E, Zochbauer-Muller S, Shivakumar L, Fong $K$, Gao B, Randle D, Kondo M, Virmani A, Bader S, Sekido Y, Latif F, Milchgrub S, Toyooka S, Gazdar AF, Lerman MI, Zabarovsky E, White $M$, Minna JD: Epigenetic inactivation of RASSFIA in lung and breast cancers and malignant phenotype suppression. J Nat Cancer Inst 200I, 93(9):69|-699.

Publish with Bio Med Central and every scientist can read your work free of charge

"BioMed Central will be the most significant development for disseminating the results of biomedical research in our lifetime. "

Sir Paul Nurse, Cancer Research UK

Your research papers will be:

- available free of charge to the entire biomedical community

- peer reviewed and published immediately upon acceptance

- cited in PubMed and archived on PubMed Central

- yours - you keep the copyright
BioMedcentral 